\title{
Palabras para Ana Amado
}

Nora Domínguez

El 10 de noviembre de 2016 falleció nuestra querida compañera Ana Amado, fundadora de nuestra Área Interdisciplinaria de Estudios de la Mujer en 1992, luego Instituto en 1997. Fue también parte del Comité de Redacción de esta revista desde sus inicios. Ana tenía dos preocupaciones con respecto a Mora: la primera, que la revista absorbiera y reflejara los debates más álgidos de la agenda feminista y para ello insistió en la apertura de la sección "Debates". Siempre tuvo claro que la práctica y el pensamiento feminista debían ser parte de una clara intervención política en el seno de una producción académica o, al revés que una revista académica no podía eludir el debate político. La segunda era que Mora debía apelar a una apuesta estética en el diseño interior y en las tapas. La lista de artistas plásticos (varones y mujeres) de cada uno de los volúmenes fue parte de una decisión suya. Para una de las últimas tapas, la núm. 19 de la versión digital, Ana eligió una serie de fotogramas de un documental, que registra la entrega de bolsas de comida que realizan mujeres a los varones 
inmigrantes que parten en ominosos

trenes a la frontera de Estados Unidos.

En esa selección se entrelazan ajusta-

damente las dos obsesiones de Ana

Amado.

El 27 de julio de este año, durante la

XIII edición de las Jornadas de Historia de las Mujeres, se realizó un homena-

je a su trayectoria al que asistieron y

recordaron, con discursos y anécdo-

tas, familiares, amigxs, colegas y com-

pañerxs. Ese día se presentó un video,

editado por su grupo de discípulxs y

a cargo de Lorena Moriconi. . En esta

oportunidad presentamos una entre-

vista que le había realizado la inves-

tigadora Sandra Carli que recorre su

itinerario intelectual en primera per-

sona. Invitamos a leer también unos

pocos mails que recibí en esos días de

su fallecimiento como testimonio tec-

nológico y actual de los sentimientos y

palabras que Ana inspiraba. También

algunos textos de Facebook que dan

cuenta de algunas aristas, muy pocas

de las incalculables que Ana Amado

desplegaba con inteligencia y pasión.
El 9 de noviembre de 2016, o:26, Nora Domínguez Rubio escribió:

No quería dejar de contarles (algunas ya saben) que Anita está desde hace mas de 15 días internada y está lentamente despidiéndose.

Escribo y no sé qué palabras usar.

Beso,

Nora

El 9 de noviembre de 2016, 10:08, Mirta Lobato escribió: Querida Nora: nosotras no tenemos la posibilidad de darle un beso, de despedirnos. Tampoco sé cómo podría ser esa situación, pero me gustaría que supiera que ella, Ana, me acompaña desde hace 15 años cuando murió Lisandro. Fue su generosidad y afecto lo que me ayudó a trasponer nuevamente las puertas de la Facultad. No puedo olvidar su imagen de cariño. Ojalá pueda sentir el cariño que le tengo y, estoy segura, le tenemos todas.

El 9 de noviembre de 2016, Ana Domínguez Mon escribió: En el mismo sentido del recuerdo de Mirta, va el mío. Ana me acompañó algunas madrugadas pensando cómo sobrellevar mi tratamiento sin saber que ella misma iba a tener que seguir otros más agresivos del que yo pasé. Una de esas trasnochadas por chat, dije algo que a ella le gustó y que pensé desde que bajamos juntas la escalera del edificio de Mónica. Es como cuando estás nadando en el mar y querés regresar a la costa. Dejarte floja, no pelear contra las olas y aprovechar la corriente para no gastar energías. La corriente misma me va a dejar en la orilla. Le encantó la imagen y me dijo que la emocionaba. Hoy ella me emociona con su entereza y la maravillosa generosidad que me regaló con su amistad.

Siento que es la única forma de estar cerca de ella en este momento.

Gracias, Nora. Imagino que ella sabe que estamos muy cerca afectivamente de ella.

El 10 de noviembre de 2016, 10:28, Mirta Lobato escribió: Queridas compañeras, no tengo palabras, por eso me refugié en Anna Ajmátova. Ellas abrazan a nuestra compañera Ana y a nosotras.

No sabemos cómo decirnos adiós:

erramos por ahí, hombro con hombro.

Ya el sol está bajando,

vas taciturno, soy tu sombra.

Entremos en una iglesia a ver

bautizos, matrimonios, misas de difuntos.

¿Por qué somos diferentes del resto?

Afuera otra vez, cada quien vuelve la cabeza.

O sentémonos en el cementerio,

sobre la nieve pisoteada,

suspirando el uno por el otro. 
Esa vara en tu mano está dibujando mansiones donde estaremos siempre juntos.

Anna Ajmátova (1917)

El 10 de diciembre de 2016, María Luisa Femenias escribió:

Lindas palabras, Mirta.

Yo nunca sé cómo ponerle palabras a los sentimientos; como dice Mirta, que sepa que la queremos mucho y que aprendí mucho con ella. No puedo decir "adiós", menos a la distancia. Besos,

M.I.

El 11 de noviembre de 2016, a las 1:55, "Mónica Szurmuk" escribió:

Me hubiera encantado estar con ustedes hoy, pero las sentí cerca todo el día y sentí muy cerca la presencia de Ana, su luz multiplicada en todas las historias hermosas que se publicaron en el Facebook, en todas las fotos tan lindas, en el modo en que iluminó la vida de tanta gente.

Les mando un abrazo muy, muy fuerte. Las quiero mucho,

Mónica

El 10 de noviembre de 2016, a las 10:35, Graciela Batticuore escribió:

Gracias Mirta: la poesía, siempre es justa para alguien tan bello como Ana...

El 10 de noviembre de 2016, Marcela Visconti escribió: Qué tristeza enorme. Estoy desolada.

Alejandra Oberti escribió:

Gente querida, comparto la tristeza de todas.

Es una gran pérdida difícil de dimensionar.

El 10 de noviembre de 2016, a las 13:29, Romina Smiraglia escribió:

Con Lucas Martinelli, Fernanda Alarcón, Julia, etc., tenemos un grupo denominado "Lxs amadistas" y cuando lo armamos lo bautizamos con esta hermosa foto. Gracias a ella nos conocimos y, gracias a su generosidad y paciencia, comenzamos nuestro camino en la investigación. El último día que pasé con ella en su casa, recuerdo que mientras peleábamos con el Sigeva (Sistema Integral de Gestión y Evaluación) y, entre idas y vueltas, a su heladera en busca de manjares para alimentarme, Ana me relataba historias sobre textos escritos, intervenciones, debates en congresos y tiernas y divertidas anécdotas sobre tesistas, ahora doctorxs, que había formado a través de los años. Fue una de las primeras personas que cuando murió mi mamá me dijo las palabras justas, si las hay...
Gracias a ella volví a escribir, recuerdo que frente a mi bloqueo me repetía "te quiero leer" y, como un conjuro, siempre funcionaba... Siempre entera, siempre con ese humor perfecto e irrepetible, una fuerza de la naturaleza... Esa hermosa fuerza que nos juntó y continuará con nosotrxs.

Nora Domínguez respondió:

Grande, Romina! Vos sos fuerte, también. Lo vi ese día del Sigeva y el otro, cuando corrimos a cuidarla.

10 de noviembre, a las 14:33, Lucas Martinelli escribió: Me quedo con algunos principios.

Filosofía y Letras. Primera vez que la vi. Clase teórica de Análisis y critica del cine, la profesora titular habla sobre Taxi driver. Explica algo sobre el movimiento de la cámara, la autonomía respecto al personaje, luego de una llamada telefónica, indicador narrativo de que algo no anda bien en su cabeza. Pienso: esta mina es una genia, ¿cómo hace para hablar así, para trasmitir esa pasión?

Plaza del congreso. En un acto por la legalización del aborto, le llevo los papeles de una beca estudiantil para empezar el camino de la investigación con su firma, de su mano.

La cocina de su casa. En una reunión, conozco, entre otras compañeras, a Julia, a Fernanda y a Romina.

Se fue su presencia física, su huella maternal en mi camino es un faro inextinguible.

Gracias, Ana.

10 de noviembre de 2016 a las 16:38, Paola Cortes Rocca escribió en su Facebook:

Te voy a extrañar para hablar de cine y de vestidos, del peronismo y de las "nenas". Para desayunar en el bar de la esquina y mirar fotitos. Te vamos a extrañar, Ani. No encuentro la imagen justa.

10 de noviembre a las 13:09, Verónica Yattah escribió: Ana Amado: una de las mejores profesoras que tuve estos últimos años en la facultad. En el final de su materia me sentí escuchada más que evaluada. Charlamos sobre "Sin techo ni ley" de Varda y de paso nos fuimos a otra escena donde otra mujer se sube a un camión: esa de "Je, tu, il, elle" de Chantal Akerman. Ella me preguntó cómo hacía Varda para hacer sentir el frío. Yo le decía: no sé, en los labios de la protagonista, cada vez más morados, en su forma de caminar para darse calor. Ella me dijo: hay que prestar atención a los colores en Vardá porque siempre en sus películas dicen algo. ¿Cómo se agradecen esas cosas que nos dicen y nos acompañan para siempre?

Lucía De Leone escribió:

Ana, mi amada. Mi profesora, mi amiga, mi cuidadora, mi interlocutora, mi mora, mi compañera de luchas, mi 
alfonsina. No dejó de llamarme ni un día cuando tuve reposo en el embarazo. Fue de las primeras en llegar al nacimiento de mi hijo Martín. Me dio los mejores consejos para bancar los primeros días con el bebé. Inmuno-deprimida estuvo en mi defensa de tesis y en el velorio de mi padre. Cuando yo entraba en pozos me convencía de todas mis potencias. La última vez que la vi ya estaba muy mal y, sin embargo, me daba ánimos ella a mí y se había ido a comprar un regalo para Martín, uno de madera, para que dure, me dijo. "Qué lindo sería que la muerte fuera temporal" me dice mi niño cuando le cuento... "así vemos a Ana más tarde". No me resigno a no verte más, Anita amada, para mí que estás en las partes más lindas del aire que corre. 